Fecha de recepción: diciembre 2017 Fecha de aceptación: marzo 2018 Versión final: julio 2019

\section{Paisajes de miedo y melancolías del destierro: exiliados políticos colombianos en la ciudad de Barcelona, España ${ }^{1}$}

Liz Rincón Suárez *

\begin{abstract}
Resumen: A partir de las trayectorias migratorias de colombianos en Barcelona, España, este artículo demuestra cómo el exilio político constituye un evento violento; escenificado y elaborado por los actores armados de la guerra colombiana, a través del establecimiento de paisajes de miedo y de terror. En este proceso irrumpe la partida y adviene la experiencia del extranjero, un extrañamiento que decanta en la necesidad de encontrar prácticas creativas para negociar la nostalgia, la sensación de pérdida y el destierro. En conclusión, la migración forzada internacional, en el prisma del exilio, tendrá como principales consecuencias la existencia en condiciones precarias, la experiencia migratoria de habitar desde la nostalgia de la tierra abandonada y del proyecto perdido.
\end{abstract}

Palabras clave: Migración Forzada Internacional - Exilio político colombiano - Conflicto armado colombiano.

[Resúmenes en inglés y portugués en las páginas 198-199]

${ }^{(*)}$ Socióloga de la Universidad del Rosario de Colombia, Master en Investigación en Sociología por la Universidad de Barcelona y Doctora en Antropología de la Universidad de Los Andes de Colombia. Se desempeña como profesora en la Universidad Los Libertadores y hace parte del Grupo Copolis de la Universidad de Barcelona y del GT CLACSO.

Colombia ha padecido 70 años de guerra declarada entre las guerrillas de vocación izquierdista, los ejércitos privados de paramilitarismo de derechas y las fuerzas del Estado. La guerra ha decantado en una lista compleja de crímenes de lesa humanidad, que ubica a la nación como la segunda nación con mayores cifras en desplazamiento interno -4.000.000- (CODHES, 2016) y la quinta en desplazamiento internacional -3200 refugiados y un importante sub-registro de cerca de 2.000.000- (ACNUR, 2018). La ausencia de conocimiento sobre el exilio y el refugio como estatus migratorios, ha hecho que millares de colombianos migren por factores de guerra, pero se desplacen con estatus de migrantes trabajadores o de fuga de cerebros. Si bien existen múltiples formas de migración forzada internacional, una de ellas, el exilio político, es, como refiere Roniger (2009), una estrategia institucionalizada de eliminación de la oposición política (Roniger, 2009, p. 84), 
391.000 colombianos han migrado al extranjero, en razón de su militancia, su pertenencia a partidos de izquierda o su resistencia frente a las acciones de los actores armados. Esto se correlaciona con el genocidio de líderes políticos que se ha agudizado a partir de los diálogos y la implementación de los acuerdos de paz entre la guerrilla de las Fuerzas Armadas Revolucionarias de Colombia (FARC) y el Gobierno del ex - presidente Juan Manuel Santos.

España, se ha erigido como el primer destino de los exiliados colombianos hasta 2008 y el cuarto en 2018. Primero, por una razón práctica de lengua y costumbres, segundo, por las redes de solidaridad que abrieron y fortalecieron los exiliados de la primera y segunda fase del exilio, es decir, aquellos líderes políticos y de izquierda que migraron durante el estatuto de seguridad de Julio César Turbay de 1978 a 1984 y en la avanzada paramilitar de las Auto Defensas Unidas de Colombia (AUC) de 1988 a 1998. Un hito fundante en la historia del exilio político será la conmemoración del 6 de marzo de 2008 que se llevó a cabo en más de treinta países del mundo. 6 de marzo fue la primera vez que los exiliados hablaron de su migración forzada y se organizaron para denunciar el exilio como hecho victimizante de la guerra colombiana.

Antonia ya había recorrido el Magdalena Medio y los Llanos Orientales cuando arribó a Bogotá. Comenzó a liderar un proyecto con mujeres, en una zona vulnerable, incrustada en los cerros orientales de la capital colombiana. En su relato recuerda las calles empinadas del barrio, un barrio joven lleno de madres con hijos adolescentes. El espacio era regulado por bandas paramilitares que, con su poder, marcaban los ritmos cotidianos. Los jóvenes tenían que cumplir con códigos impuestos de vestido, que se asemejaban a la estética militar y representaban el orden corporal dominante. Se impartían castigos a quienes incumplieran las normas, algunos eran colgados desnudos en las canchas de baloncesto y expuestos en medio de la noche, bajo temperaturas que llegaban a los cinco grados centígrados en la altura de los cerros. No era nuevo que las mujeres en el contexto del conflicto armado colombiano opusieran resistencia a los actores armados, la organización de Antonia, famosa en todo el territorio nacional por no entregar a sus hijos al reclutamiento forzado y por denunciar la violencia sexual, había descubierto que en la ciudad también se habitaba en el contexto de la guerra y el confinamiento.

El proceso de denuncia inició, los jóvenes eran desatados de las canchas o bajados sus cuerpos hipottérmicos en las horas de la noche. "Le hicimos el amor al miedo", refiere Antonia. Los actores armados respondieron con diferentes mensajes, uno llegó al comedor comunitario donde las mujeres se reunían. Dentro de una caja, una cabeza de perro con sus vísceras le advertía a Antonia que debía salir de la ciudad. El mensaje siniestro comunicaba más que una simple amenaza de muerte, Antonia y su ejercicio eran traducidos en la figura de "la perra", un insulto común colombiano conocido como una de las principales ofensas para las mujeres que desacatan la norma. Intentó permanecer en el país, pero no era la primera vez que amenazaban a su familia, dos de sus hermanos habían tenido que salir por sus militancias en el partido comunista, ahora el turno era para ella.

La amenaza se nutre de las imágenes e imaginarios comunes. Dentro de la guerra colombiana se han creado significados compartidos entre enemigos, que se traducen en imágenes. Un ejemplo de ello es la adaptación de los sufragios fúnebres, una tradición colombiana que comunica condolencias por la muerte de una persona conocida, para hacer parte 
de los rituales de hostigamiento. Durante los años ochenta, los sufragios fueron utilizados para anunciar la muerte de los líderes, comúnmente enviados por los carteles del narcotráfico. Esta práctica fue apropiada por los grupos paramilitares durante su consolidación en la década de los noventa y se sigue utilizando hoy en día junto con la publicación de listas y panfletos.

El panfleto es un vehículo de comunicación de los actores armados. Donde se pone en escena el actor perpetrador, el actor víctima y los significados alrededor del enemigo. Esta puesta en escena hace parte de los repertorios violentos de alguno de los contendores de la guerra, en su mayoría actores paramilitares. Tilly $(2002$, p. 8) explica el concepto de repertorio:

Los repertorios son las puestas en escena en las que organizaciones políticas hacen reclamos ante un actor político. Esta representación pública es "un conjunto limitado de rutinas aprendidas, compartidas y actuadas a través de un proceso de elección relativamente deliberado.

Ahora bien, un repertorio político se transforma en un repertorio de violencia cuando:

Son producto del emprendimiento de unos empresarios de la violencia que aprovechan ciertas condiciones para definir unas identidades políticas favorables que, en el caso de las guerras irregulares, tienen el objetivo de establecer un control territorial. Sin embargo, los actores armados deben implementar una variedad de formas violentas para cumplir con sus objetivos (Moreno León, 2012, p. 87).

Con el fin de caracterizar los modos de operación de los actores armados, Moreno (2012) identificó cuatro modalidades del repertorio de violencia en el suroccidente colombiano. El enfrentamiento armado, la amenaza, la violencia física, y el ataque a la infraestructura física y la extracción de recursos. En el desplazamiento forzado convergen varias de estas categorías. Sin embargo, la amenaza es uno de los más señalados por los exiliados como el comienzo de su trayectoria de desplazamiento, que en muchos casos inicia con desplazamientos intraurbanos, internos y decanta en internacionales. La centralidad de la amenaza en los relatos la convierte en el punto de quiebre en las vidas de las personas exiliadas:

La promesa de efectuar una acción violenta en el futuro a partir de un cambio de conducta presente. Las amenazas deben ser clasificadas a partir de la presencialidad de la conminación y del grado de especificidad de la intimidación (Moreno León, 2012, p. 87).

Para lograr la mayor efectividad los actores armados desarrollan labores de inteligencia que les permiten identificar los contenidos simbólicos más apropiados para imprimir terror. En las amenazas hechas a mujeres defensoras existe un mayor énfasis en el contenido simbólico. El panfleto dirigido a Lilia, líder del partido político Unión Patriótica (UP), tiene a la muerte sosteniendo a una rosa, el mensaje viene además con una bala y lo acompaña una corona de flores. Estas metáforas dan cuenta de las ideologías detrás 
de los panfletos y sus contenidos. En el caso de Antonia se utiliza la violencia de género, muy frecuente en los estados de guerra, donde las líderes son asociadas con prostitutas y se utilizan imágenes de animales -como el perro-, como forma de deshumanización por considerarlo auxiliadoras de la guerrilla y por tanto no humanas.

Como se evidencia, el detalle de las representaciones de las amenazas tiene una estrecha relación con la crueldad, entendida esta como una forma de imprimir sufrimiento sin responder a sus efectos con la compasión o con la piedad (Regan, 1980). La crueldad se asocia con la estructura del poder que usa como ley la violencia y que toma los cuerpos fuera del sentido sacrificial para usarlos como trofeo de guerra, y en ocasiones, demuestra goce frente al sufrimiento que se imprime (Sharpe \& Mascia-Lees, 2006). Es así como afecta el sentido a través de metáforas que se han construido en los registros simbólicos comunes y que contiene en la mayoría de los casos un marcado diferencial de género: rosas abrazadas por la muerte para las mujeres, balas y sujetos armados para los hombres.

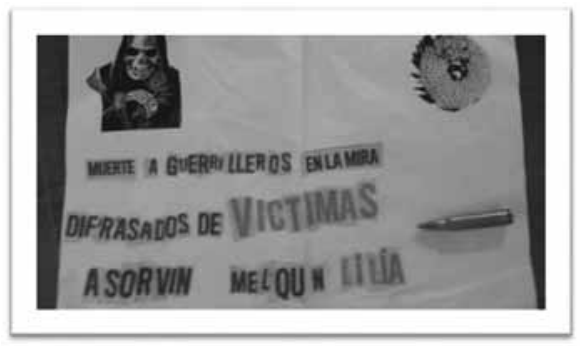

Figura 1. Panfleto de amenaza a la líder del partido UP Lilia Peña (Radio Macondo, 2014).

Continuando con las formas racionales de crueldad, Alicia, en el balcón de su casa, relata cómo "las fuerzas oscuras" han desarrollado formas cada vez más elaboradas para enviar las amenazas. Cada historia es distinta y tiene un mensaje particular, únicamente los panfletos colectivos, que involucran treinta o cuarenta nombres propios, son masivos y con el señalamiento común hacia los defensores como guerrilleros. En el caso de los panfletos personales o de las amenazas se utilizan los teléfonos celulares o el correo electrónico, y en algunos casos, la irrupción en la casa. Andrés encontró a unos policías en la puerta que reían, posteriormente encontró que habían entrado a su apartamento y se habían llevado su computador portátil y todas las informaciones que asociaban a militares con la desaparición de su madre. Después de este hecho y evaluando su riesgo decidió exiliarse.

Si bien se ha relacionado la crueldad con la bestialidad y la locura, los procedimientos de quienes amenazan no parecen obedecer a este ámbito fuera de lo humano o al pathos psicológico, al contrario, responde a una elaboración consciente y colectiva sobre lo que significa el enemigo. Frente a estos rituales y significados "lo que los vuelve profundos es que la reproducción precisa de movimientos, la enunciación de ciertas palabras que no 
cambian, el uso invariable de determinados colores o instrumentos, van unidos a emociones que cada vez adoptan matices diferentes" (Ovejero, 2012, p. 20) y que afectan directamente al amenazado. Esto supone entonces el punto de partida para la instalación, concordando con Oslender (2012), de paisajes de miedo en lo cotidiano, pues la amenaza es el punto ritual de partida para situar la probabilidad de muerte en la cotidianidad de la persona y con esto restringir sus movilidades, romper las interacciones de confianza y en palabras de Oslender "transformar dramáticamente su sentido de lugar" (2012, p. 174 ). El relato de Alicia, ejemplifica cómo se introduce el miedo en los paisajes y ritmos cotidianos. Alicia relata como a finales de noviembre un panfleto le anunciaba a su compañero que tenía hasta el 31 de diciembre de ese año para salir de la ciudad de Bogotá. Almorzaron en el restaurante de todos los días en el centro de la ciudad. Al despedirse vio un carro azul que se aproximaba en el carril del Transmilenio -trasporte público-, prohibido para automóviles, se quedó con la mirada en su pareja que se alejaba por la esquina mientras el carro azul seguía el mismo trayecto "sentí un vacío y ganas de gritar, pensé que ese carro se lo iba a llevar", narra Alicia, "pero el carro dobló en otro sentido y decidimos no volver a almorzar en los mismos lugares de siempre".

Los mensajes no solo se encargan de poner una fecha límite a la vida de los defensores, romperán los cursos de la acción, con lo cual el efecto puede verse en esquemas de interpretación ambiguos como la incertidumbre frente a las interacciones cotidianas con vecinos o desconocidos, interacciones basadas en la desconfianza y en la ansiedad. Baste como ejemplo la conmemoración de 6 de marzo de 2011 del Movimiento de Víctimas de Crímenes de Estado en Bogotá. Uno de los organizadores me comentaba la importancia del cuidado con las personas desconocidas mientras conversábamos. La desconfianza por el saboteo tenía a su vez la preocupación por "la infiltración" el mecanismo desde donde los agentes de la inteligencia paramilitar o militar identifican a los líderes sociales y sus entornos de significado, para luego abrir el paso a la creación de listas -señalamientos de nombres propios y anuncio de su asesinato-.

Otro rasgo de la experiencia de habitar en el paisaje de miedo es la conciencia sobre la propia muerte, se asienta en el entramado simbólico de lo cotidiano, constituido por los objetos, las imágenes que hacen parte de los paisajes, y en los ritmos de desplazamiento, en los cuales se entrecruzan personas, rutinas, acciones y significados. Precisamente en estas geografías diarias que establecen los sujetos, se instalan los mecanismos del terror. En este sentido, las partidas estarían incididas por la construcción juiciosa de una desnaturalización del mundo percibido como común, para volverlo siniestro, para transformarlo en un espacio ajeno. En el siguiente relato, Roberto, ex fiscal cuenta como su vida giraba alrededor de la persecución:

A mí me hacen un atentado el 16 de septiembre de 99. Me salve como las pulgas porque al tipo se le cayó la pistola y yo alcance a acelerar mi moto, pero a mí me persiguieron, y logré meterme a la fiscalía. Siempre me amenazaban diciéndome que yo estaba en el cuarto renglón de la lista de las autodefensas, que yo figuraba como ideólogo de la guerrilla. Dos años antes de que mataran a mi hermano la procuraduría me había anunciado que yo era ideólogo y testaferro del cartel del Norte del Valle, todo porque choqué con un sargento de la policía 
por situaciones de procedimiento y derechos humanos. Toda esa situación fue creando ese caldo peligroso (Entrevista realizada por Laura Becerra Elejalde, 2012).

En otra arista a la experiencia de Roberto, la respuesta social más frecuente en los defensores ante las amenazas es o bien naturalizar la crueldad como parte de las consecuencias por el hacer activista o negarla, "eso no es para mí" referiría Antonia al recibir el mensaje en la organización donde trabajaba. La característica de ser mujer la vuelve un objeto de la fuerza, una "cosa" y borra la complejidad de su existencia femenina y de su proyecto feminista no violento.

Pese a que el mensaje es claro, la sensación de no comprender lo sucedido la atraviesa, no existe un acervo a la mano con el que pueda interpretar lo que está ocurriendo y no espera bajo ningún motivo que el efecto sea el exilio. Algo similar ocurre con Elsa, la amenaza no es del todo asumible, no hace parte del relato central de su trayectoria de vida, es un silencio, no lo narra, como si da un salto para contar el ejercicio político por el cual fue obligada a migrar o retorna el relato hacia su evolución como líder en España. La amenaza para muchos se transforma en un silencio, en muchos casos voluntario, pues cuando comenzó esta investigación, el exilio constituía un secreto, hecho que se transformaría después del inicio de los diálogos de paz en la Habana, Cuba pues la paz en Colombia, supondría que el estigma ya no operaría en el contexto, debido a que no existiría el enemigo guerrillero ni tampoco el auxiliador de la guerrilla.

Para comprender el paisaje de miedo, Simone Weil (1996), resumiría este modo de habitar en el mundo como la tensión entre la muerte y el porvenir. El habitar los paisajes de miedo, supone que los días se perciban como un presente vertiginoso:

Aquellos cuya alma está sometida al yugo de la guerra, la relación entre la muerte y el porvenir no es igual que en los otros hombres. Para los otros es un límite impuesto de antemano al porvenir, para ellos es el porvenir mismo, el porvenir asignado a su profesión (...), el alma sufre violencia todos los días (Weil, 2007, p. 12).

Estas formas de imprimir violencia, se dan en varios niveles de la experiencia subjetiva, en un nivel emocional que los sobrecoge y que para algunos es más fácil de comprender que para otros, en un nivel corporal porque su cuerpo que antes representaba un patrimonio personal, se transforma en un cuerpo-objeto, un lugar para la muerte y en los ritmos cotidianos, que se trastocan y estarán mediados por las estrategias de protección o por el establecimiento de relaciones con intensidades emocionales que generan un desgaste, un duelo por el inminente abandono del proyecto familiar, político o social. El exilio es una opción lejana, "huir" como manifiesta Valentina, "no corresponde con lo esperable en un activista de derechos humanos, como sí resistir".

Así las cosas, los antes sufragios son reemplazados por notas que vinculan las imágenes de la muerte y el funeral, coronas de flores, imágenes de cráneos. La amenaza aparece como algo que se espera en las vidas de los defensores, pero no siempre es asumido como posible, es casi un mito fundador en la historia del activismo colombiano. Una forma de 
elaborarla es el humor negro, como ponerles apodos a los grupos paramilitares, $\mathrm{o}$ asegurar tener planes para sus propios funerales, como canciones, poemas o formas en las que sus seres queridos deben asumir su muerte. Valentina relata como su padre se despedía de ella cada día y le advertía que podrían asesinarlo.

Otras formas de elaboración responden a la salida creativa, como las piezas comunicativas "No nos callarán" lanzadas en 2014 por los medios alternativos o la campaña de las mujeres "Hacerle el amor al miedo" en 2012. En el primer caso se presenta un video donde los defensores usando marionetas explican en que consiste amenazar e identifican como fin de los panfletos el fortalecimiento de las redes de solidaridad entre las organizaciones sociales; en el segundo caso, la campaña buscó quitar el significado a las acciones de terror y en cambio resistir con respuestas amorosas y no violentas.

Uno de los efectos más impactantes de existir en el paisaje de miedo es la naturalización de la muerte como efecto del trabajo político, el cual parece hacer parte del día a día, "si nos amenazan es porque lo estamos logrando, estamos poniéndole el ruido a esta gente que no quiere la paz" dice Pablo, tras recibir un panfleto de la banda criminal "Los Rastrojos" que le pone a su cabeza un precio de diez millones de pesos.

Aunque algunos evalúan de manera positiva las amenazas como estar en el curso exitoso del trabajo político, el daño se manifiesta incluso en esta misma naturalización. Genera sufrimiento cada vez que vuelve a aparecer, pues introduce a los sujetos en cadenas de ansiedad, paranoia y miedo. Entonces deviene la sensación de extrañamiento y negación, el "eso no es para nosotras" de Antonia, que retorna a un momento en que se carece de comprensión para asumir la realidad del hecho violento: la alta posibilidad de ser asesinado. A su vez, la crueldad del "ejemplo" un lugar frecuentemente enunciado en los actores armados sobre todo del paramilitarismo, tiene entonces éxito en la medida que instaura el miedo al daño y, en consecuencia, el abandono o debilitamiento de los proyectos sociales. Con este fin la crueldad se instala en el espacio físico y material. El objetivo de desarticular el mundo conocido y habitado de las comunidades incluso en los niveles más cotidianos transforma objetos de afecto en herramientas del poder para infligir terror, dándole un doble significado a dichos objetos. Son los objetos más familiares de la vida hogareña celulares, fotografías familiares, objetos relacionados al proyecto social y político o a sus actores-, los que pueden transformarse en los objetos del horror como medio para desarticular el mundo de la persona. El celular, por ejemplo, es uno de los objetos con doble significado, pues es una herramienta de protección y cuidado, pero a su vez es el primer lugar donde generalmente se reciben las amenazas.

Algo similar ocurre en el caso de las cámaras de los periodistas. En diciembre del año 2014 un panfleto general, de la banda criminal paramilitar Águilas Negras, amenazaba a los medios alternativos, las amenazas nombraban a la red de Patricia, corresponsal de un medio alternativo colombiano en Barcelona. El panfleto cuidadosamente elaborado usaba frases como "los grabaremos y tiraremos su cuerpo al río". La cámara, el elemento más significativo de este ejercicio se transforma en un objeto de terror, de documentar la propia muerte, como se documentaron las iniciativas de resistencia o las denuncias por las violaciones y vejámenes de los actores armados.

De manera semejante, Margarita experimentó la amenaza a través del “ordenador", el único objeto que se llevaron al entrar ilegalmente en su casa. Desde el ordenador -computa- 
dor- recibió el correo electrónico que le anunciaba un plazo de pocos días para abandonar el país por su trabajo de formación en derechos humanos a agentes de la fuerza pública. Sin embargo, los objetos no son el único escenario de desarrollo de formas de crueldad, también los lugares familiares deben convertirse en lugares siniestros, desconocidos como en el caso de Alicia.

Siguiendo con la relación paisajes de miedo y cotidianidad, en las amenazas paramilitares existen diversas maneras de utilizar símbolos espaciales de las comunidades como ríos, plazas o en general espacios de socialización que tienen una historia local relevante para llevar a cabo las masacres (ACA 2010; revista Noche y Niebla 2008; Grupo de memoria Historia 2010; Bello 2005). Un hito en la memoria de los defensores es el caso de la cancha de baloncesto en el Municipio del Salado, que fue transformada, de sitio de encuentro y esparcimiento deportivo, al lugar donde se ejecutó la masacre entre el 16 y el 21 de febrero del 2000 y donde actores paramilitares del Bloque Norte, comandados por Jorge 40 asesinaron a 60 personas (Grupo de Memoria Histórica, 2009). En el testimonio de los sobrevivientes "jugaron fútbol con las cabezas de los campesinos señalados de guerrilleros". Otro caso relatado por los defensores es que luego del desplazamiento masivo de los campesinos, los municipios y caseríos se han venido transformando en pueblos fantasmas donde el retorno es impensable. Los paisajes de miedo, por tanto, consisten en cómo la realidad de los activistas es asumida desde la negación total de la dignidad del sujeto, quien habita el mundo a merced de su perseguidor.

Como efecto, el paisaje de miedo causa el confinamiento o la fractura del hogar y del circuito cotidiano como estrategia de supervivencia. En esta lógica la amenaza que se pone en escena a través de panfletos, cartas, correos electrónicos o comunicados masivos, tienen por objeto evidenciar la vigilancia sobre las acciones de los defensores. La amenaza recurre generalmente a utilizar referentes conocidos por las personas de tal forma que aseguran un cambio en las rutinas cotidianas de los defensores, quienes establecen unos circuitos de acción política y de existencia mediados por el temor a la muerte.

Por lo tanto, después de la amenaza viene el vértigo de la vida cotidiana rota, es decir un estado de hipervigilancia que finaliza en la decisión de la salida forzada, que se efectúa bajo una alta cuota de sufrimiento por el sentimiento de los defensores de estar abandonando el proyecto. Son estas interacciones en la realidad de la amenaza y la ambigüedad sobre su certeza lo que produce finalmente el daño, por un lado, se cortan los procesos organizativos, lo cual decanta en lo que Erikson denomina unos estados de ánimo comunitarios (Erikson, 2011), que rodean la tristeza y la desesperanza o que se manifiestan con el miedo y la ansiedad. Por otro lado, romperá las estructuras subjetivas de sentido de los sujetos amenazados, es decir la conciencia sobre el mundo conocido muta, en tanto el mundo que los defensores habitan es el de la muerte como porvenir inmediato. Al respecto Antonia relata:

Estos mensajes dañan mucho la estructura familiar, los procesos, el trabajo. Ya tú no hablas con la gente, no sales con tus hijos a la calle, ya estoy en la "maní" (manifestación) y mi hijo va por un lado y yo voy por otro para que no nos vean juntos. Y de cara a chicos que estas formando, que estás haciendo personas humanas sobre la base de la solidaridad y del apoyo a la gente, de ser buenas personas, como le hablas sobre la solidaridad cuando le tienes que 
decir "no le abras la puerta a nadie por más que te diga que se está muriendo o no contestes el teléfono o no te pares en la calle a hablar con nadie (Entrevista realizada por Liz Rincón Suárez, 2012).

El relato de Antonia, nos lleva a pensar esta fractura no solo como una experiencia de sufrimiento para quien la trasiega, sino también como un proceso de trauma social. Antonia, por ejemplo, sugiere que la gran paradoja que la guerra ha puesto en su vida es romper con el valor fundante de su activismo "la solidaridad" y con el principio de herencia de las luchas. Aquí el sentido se rompe y al ser un sentido construido colectivamente, afectará también al proyecto político del grupo de Antonia, quien se pregunta “ipor qué nos pasa a nosotras?". La situación de habitar paisajes de miedo, se percibe como un trauma, en la mirada de Jeffrey Alexander (2003), esta fractura es:

La pretensión de haber sufrido algún daño primordial, la expresión manifiesta de la profanación sobrecogedora de algún valor sagrado, una narrativa sobrecogedora de un proceso social terriblemente destructivo y una demanda de reparación y reconstitución emocional, institucional y simbólica (2003, p. 93).

Para ilustrar mejor este estado comunitario de fractura, examinaré el caso de las líderes afrocolombianas en Triana, parte de la red de trabajo de Anamilé, en el municipio de Buenaventura. Janeth, líder de la Asociación de mujeres y hombres de Triana, cuenta cómo en las veredas solo quedaron los hombres, las mujeres tuvieron que asumir la organización para obtener justicia para sus muertos. Sin embargo, en Triana existe por momentos la desesperanza "aquí no hay salida, aquí no va a pasar nada, los pican, los metían en bloques de cemento y ahora disque los muelen" relatan las mujeres. Estos estados de ánimo comunitarios, ese convivir con el miedo remite a la sensación de pérdida. La sensación es la que relata Veena Das (2008) sobre el contexto de la violencia y su fuerza "pero el mundo tal y como era conocido en el día a día es arrasado" (Das, 2008. p. 34). Otros estudios referenciarán también, cómo la guerra se inserta en los órdenes de significado de la cotidianidad suponiendo la pérdida de lo conocido (Blair, 2002, 2003; Castillejo, 2010; Grupo de Memoria Histórica, 2009; Jensen, 2003; Mcilwaine, 2014; Ries, 2002; Roy, 2008; Shepler, 2005), y por tanto la aparición del estado de tristeza como el lugar existencial de la víctima (Caruth, 1993; Feldan, 2004; Smelser, 2011; Vetzberger, 1997).

En conclusión, lo que ocurre con el establecimiento de los paisajes de miedo a partir del repertorio de la amenaza, es un proceso de ruptura a partir de primero, la desestructuración de la sociedad aspiracional de los valores bajo los cuales se está luchando y segundo, la pérdida de la incertidumbre sobre el porvenir de la muerte, lo cual produce existir y habitar bajo el miedo.

Alfredo relata cómo las amenazas de la guerrilla no solo llegaban por su trabajo en construcción campesina y comunitaria, sino que además se agudizaba por las constantes extorsiones de las que era víctima. Al respecto narra Alfredo "no podía pagar el fusil que luego me iba a matar". Dejó el campo y tuvo que migrar a la ciudad mientras organizaba su viaje a España. De dónde resulta, que tanto la amenaza como los paisajes de miedo establecidos por los actores armados, son el preámbulo del verdadero repertorio de vio- 
lencia: el desplazamiento forzado transfronterizo, pues siguiendo a Moreno (2012) y a Tilly (2006), estos repertorios finalmente se dan entre los contendores de la guerra para ganar escenarios y lograr el control territorial. Con el exilio, los defensores presenciarán el advenimiento del desarraigo como una (re)victimización y habitarán no solo el miedo sino también el duelo. En palabras de Claudia Girón activista retornada de la Fundación Manuel Cepeda Vargas:

La gente vive en un paréntesis de nostalgia y tristeza y en muchos casos nunca se adapta a las sociedades donde están y no se sienten parte de un nuevo mundo, sino aislados. El exilio es una condición muy complicada existencialmente. Lo duro que es el haber sido alguien en tu país y llegar a un país donde uno se vuelve un ser monotemático, porque solo habla de lo poco que conoce (Entrevista realizada por Liz Rincón Suárez, 2012).

Este paréntesis de nostalgia, inicia con las partidas, que para muchos exiliados constituye un momento del vértigo. En Barcelona, me encuentro con Leo y recuerda como en una secuencia rápida de sucesos: su teléfono celular sonando, una llamada de la fiscal que lleva el caso de su hijo asesinado; luego ella manejando la camioneta y pidiéndole que se suba rápidamente. La recuerda en la camioneta susurrándole "apaguen los celulares, saquen las baterías y las tarjetas SIM". Todavía rememora con claridad como pararon en un restaurante a las afueras de la ciudad y ella compró chicles para ponerle a un micrófono que habían encontrado antes de recoger a Leo. Luego recuerda un par de llamadas desde el restaurante y la sugerencia de cambiar de camioneta para en ella ir hasta el puente internacional del Aeropuerto El Dorado. Todo se hizo como la fiscal resolvió, la maleta de Leo iba en camino y él partió a España, me dice entre risas "a veces tenemos despedidas y a veces no". En contraste Alfredo planeo su salida después de que el frente del Comandante Romaña que operaba en el Sumapaz, le exigiera "la colaboración con la causa" cuando Alfredo no pudo pagar, su mujer huyó a Barcelona y él la siguió meses después con sus dos hijos. Alfredo recuerda el vértigo en la estación de tren y después de haber llegado a la casa donde se hospedaba su esposa en un cuarto, en el mismo en el que tuvieron que dormir y habitar los cuatro durante meses, antes de que él encontrara trabajo como obrero, sin papeles.

En suma, los paisajes de miedo se experimentarán en rituales como las despedidas, informar sobre la ubicación y el bienestar de la persona cada cierto tiempo, acogerse a los protocolos de seguridad y protección de las organizaciones solidarias o de acompañamiento internacional, diversificar los circuitos por donde se movilizan, cambiar constantemente las rutinas, los medios de transporte o sus compañías, asumir que los teléfonos están siendo interceptados y reducir las conversaciones a lo mínimo, son interacciones que están definidas por la frecuencia de casos de persecución política en la comunidad afectiva, cuyo fin último es la muerte.

Finalmente, los paisajes de miedo serán el tránsito al DTF. Cuando se pasa la frontera y se llega al nuevo destino, una sensación de irrealidad atraviesa a muchos. Algunos apenas pueden procesar lo que ha ocurrido, otros se acomodan o hacen del exilio un silencio. A continuación, examinaré la llegada de los exiliados y cómo la nostalgia atraviesa la existencia en el extranjero. 


\section{El extrañamiento del mundo y la necesidad existencial del silencio}

La noche que Alfredo llegó a Barcelona, ni siquiera sabía que allí hablaban una lengua distinta de la suya. Se sentía confundido. En el verano de 2012 en Hospitalet de Llobregat, su mirada se pierde por un momento, guarda silencio y narra:

No sé si alguien ha olido la amargura, yo creo que sí, yo he olido la amargura. El desarraigo es una de las violencias más fuertes que hay, es algo que taladra el corazón, el pecho, el alma, el olor de la noche interminable, el silencio de cuándo uno pide ayuda y a veces calla y no viene. Algo que me aterraba era subirme al metro, tuve que hacer un trabajo para quitarme de mis oídos y de mi mente cuando decían -próxima parada: Lesseps (Entrevista realizada por Liz Rincón Suárez, 2017).

Una de las afirmaciones más recurrentes en los relatos de los defensores es “aquí me siento como extranjero" o "estoy lejos de mi tierra" el arraigo, es un proceso que va más allá del ejercicio político para hacer parte de la condición humana y su necesidad de pertenecer. El exiliado es un desplazado en tierras extrañas, su arribo coincide con la experiencia narrada y explicada por Park (1928); Simmel (2012); Schütz (1999); Weil (1996) y Elías (1994) todos ellos referían a una relación clásica en la trayectoria del extranjero (Simmel, 2012), el Forastero (Schutz, 1999) o el hombre marginal (Park, 1928) y representa la ruptura entre la familiaridad y la intimidad para abrirle paso al extrañamiento del mundo. Este proceso de ser "el otro" será vivenciado de manera diversa en las trayectorias. Como refiere Simmel (2012):

Si la distancia dentro de la relación significa la lejanía de lo cercano, el extranjero significa la cercanía de lo lejano. (...) El extranjero es un elemento del grupo como también lo son los pobres y los distintos "enemigos interiores". Es un elemento cuya posición supone al mismo tiempo exterioridad y confrontación (p. 21).

Una definición similar la tendría Alfred Schutz (1999) al explicar que para ser forastero -su categoría análoga-, no se necesita necesariamente salir de espacio común. Si bien, en la experiencia de los sujetos ya dentro del contexto territorial del estado nación, el pertenecer a los movimientos sociales les produce un habitar el mundo desde la experiencia del extranjero. Por lo tanto, el viaje agudizará la sensación de no pertenecer, por lo menos en un primer momento de la de migración a otro territorio.

Para los exiliados la distancia provee un marco para comprender el dolor o por lo menos una oportunidad para comprender lo que ocurrió, inevitablemente dentro de las primeras fases de adaptación, ese dolor permanece como una zona de claroscuro en la cual recordar es casi como una obsesión para algunos y en contraste, otros demandan el ejercicio del olvido como una necesidad personal para superar el duelo del destierro. El elemento que está en duelo en el destierro es "el hogar" constituido por la sensación y las relaciones de intimidad y familiaridad, pese a la sensación melancólica del destierro "existe una manera 
rutinaria de tratar lo novedoso" (Schutz, 1974, p. 110). Baste como ejemplo, el relato de $\mathrm{Ana}^{2}$, quien narra cómo fue muy importante la red catalana que la apoyó a su llegada:

Al principio tuve mucho miedo y angustia porque además “eso" (el exilio) implicaba un cuestionamiento de la vida que yo tenía allí y del lugar que yo me había ganado allí, pero luego por suerte (...) fue más fácil hacer frente a la situación porque tenía una red de amigos, tenía gente que me apoyaba y acompañaba. Al principio tenía temor de integrarme a grupos colombianos porque en ese tiempo decían que había muchos infiltrados (p. 110).

Siguiendo el relato de Ana, para la mayoría de los defensores, auto representarse como exiliados no ha sido fácil, sin embargo, este hecho empieza a transformarse desde los diálogos de Paz de la Habana, debido a la posibilidad de la terminación del conflicto y las polarizaciones derivadas de este. Empero durante más de treinta años los defensores han tenido que esconder el exilio. Este hecho tiene que ver con que, por un lado, representa la marca de alguien que "podría ser guerrillero" es decir terrorista. Pero también es la marca de quien ha "huido", y, en consecuencia, su existencia se encuentra atravesada por la culpa, de tal manera que uno de los patrones en las trayectorias es asumir el exilio desde su invisibilización.

Con el estigma rodeando el desplazamiento, un muro de silencio ronda las voces que parecen profesionalizarse a través de la narración de libretos, no únicamente en el testimonio del acontecimiento violento sino también en las historias sobre la resistencia -el proyecto-. El silencio es la evidencia de lo roto en el proceso de las partidas. Lo que no se nombra es finalmente cómo se quebró la cadena de significados sobre la vida y con esto se genera una distancia entre el acontecimiento y la representación del mismo. Lo fracturado son las representaciones simbólicas "caracterizaciones de los acontecimientos pasados, presentes y futuros que se forman en la sociedad" (Alexander, 2011, p. 139).

Pongamos por caso el recuerdo de Pablo sobre el arribo de sus amigos. El mundo de algunos de los exiliados representaba "la muerte en vida", Pablo los describe como seres casi fantasmales, como personas con una tristeza totalmente arraigada, en donde la estrategia de amenazar, de generar un temor para sacar a la persona, desarticularla y matarla en vida había funcionado, los derrumbó. Pablo narra:

Era una cosa muy triste, gente que en Colombia tenía mucha fuerza, que tú veías aquí de psicólogo, de psiquiatra con unas depresiones tremendas. Yo en cambio solo había recordado que tenía el estatuto de asilo cuando estaba en el aeropuerto y no sabían qué tipo de pasaporte tenía y me decían -que esto que es, que esto no es un pasaporte colombiano, no es un pasaporte español, que es azul, que usted pa' donde va, usted de donde viene (Entrevista realizada por Liz Rincón Suárez, 2017).

En la narración de Pablo, el evento violento viene a afectar la subjetividad de los sujetos, así las cosas, "cuando no se escoge conscientemente, no se es completamente sujeto" (Van Alphen, 2011, s/p), pues la salida constituye un hecho involuntario, no planeado, no ima- 
ginado y por tanto la sensación de frustración y de impotencia conlleva a largos estados de depresión. Estos límites para la acción y la dificultad de explicar el evento violento, que en este caso lo constituye la amenaza, la persecución, el hostigamiento y el DFT, imposibilita que se involucre la salida y el arribo como una vivencia pasada y ancla a los sujetos en la melancolía y en la ruptura.

En medio de la melancolía, la casa será la primera conquista del exiliado, que en la infraestructura de la nueva sociedad será inmigrante. Tendrá que aprender cuáles barrios habitar y se asentará en los cinturones obreros y en el centro de la ciudad, asumirá cuánto cuesta el alquiler y cómo son las dinámicas para obtener un espacio propio. A menudo el habitar no se da en un contexto de derecho, Valentina narra cómo llegó "a una casa patera" donde vivían muchos inmigrantes colombianos y tuvo que compartir un pequeño cuarto, Alfredo cuenta que al inicio tuvo que vivir de la caridad de algunas casas de conocidos y familiares hasta de cuarto grado. "Te acostumbras a cargar con poco porque tienes que moverte de barrio en barrio hasta que encuentras una habita, un lugar donde quedarte o te quedas en la ocupa". La ansiedad del mundo de afuera y la melancolía, hacen del cuerpo del exiliado un cuerpo fijo en el espacio privado de la nueva casa.

Una vez conseguida la habitación o "el piso" -apartamento-, este se transforma en un refugio, pero la imposibilidad de movilizarse da cuenta del carácter del exilio como una muerte en vida. Cuando por la superación de la ansiedad se desplaza el cuerpo inmóvil del exilio y se involucra a través de parentescos, localidades o profesiones, entonces dejará de ser un extranjero e iniciará el proceso de habitar el mundo desde una asimilación total del nuevo espacio, o desde la capacidad de movilizarse a partir del encuentro con otros. Tal como lo advirtió Um (2012, p. 832), en su estudio con refugiados camboyanos, la sensación transmitida por los sobrevivientes es la de vivir con "un cuerpo y dos vidas" (p. 832). Los recuerdos de la comida y las calles, de las personas abandonadas se comienzan a habitar a través de la virtualidad de las redes sociales y de los softwares de comunicación. La Colombia advertida por los exiliados a su llegada se limita a los fragmentos que recibe en los medios de comunicación. En este punto, el país como narrara Imelda Daza, se convierte en una obsesión idealizada y se persigue en la cotidianidad de Barcelona. Examinemos el relato de Ana:

El exilio se siente a Nostalgia, lo extrañas todo, hubo una época que solamente quería comer a algún sitio colombiano, extrañaba mucho las papas criollas y allá no se consiguen lo mismo que la morcilla, entonces a veces me mandaban con familiares que iban a visitarme La música que escuchaba en Colombia cuando la escuchaba allá eran mis momentos de contacto con el país, me encantaba escuchar y bailar salsa, organizaba fiestas en las que ponía la música que escuchaba cuando vivía allá, eso me transportaba mucho (Entrevista realizada por Liz Rincón Suárez, 2018).

A la par de la nostalgia y la melancolía, las necesidades básicas hacen que los exiliados replanteen los modos de supervivencia. Alfredo, por ejemplo, pasó de ser un arquitecto en Bogotá a trabajar en la construcción cuando tuvo que arribar Barcelona tras no pagar la vacuna que le imponía la guerrilla de las FARC. Alfredo relata ese tiempo como algo que 
se extendió para siempre, ser obrero de construcción le permitió tener un lugar para su familia y cuestionar la clase social y el poder de relaciones arquitecto - obrero "somos una sociedad arribista" dice Alfredo. Luego tras la crisis económica de 2008, su vida se afectaría de manera directa por la caída del sector de la construcción.

En ocasiones las coyunturas de la nueva vida, no permiten que se elaboren estas situaciones límites, pero si mantienen a los sujetos en la realidad siniestra de la pérdida, la persecución y el miedo; o en la sensación del anonimato y la percepción de ser diferente, en este caso, en la sociedad catalana. El trabajo subjetivo, dice Kaufman (1998), será entonces la lucha entre el sufrimiento y la necesidad de dotar de sentido al acontecimiento violento, traumático, esta lucha que supone la reinvención de la identidad del sí mismo en un nuevo. Continuando con los modos de supervivencia, estos se relacionan directamente con las partidas, las redes y el estatus migratorio que se decide. La mayoría de ellas se realizan por la gestión personal de los amenazados, quienes activan sus redes de amigos o familiares. En cualquier caso, el estatus de asilo no será una opción para los exiliados, pues en su opinión no solo es una marca, sino que también es restrictivo pues con el pasaporte azul, no se puede transitar libremente, tal como señalaban Ana y Pablo. Pero a su vez, las salidas por lo general son vertiginosas y no dan tiempo de resolver los papeles en los tiempos que esto requiere. De tal manera que se debe ingresar con otras estrategias, como Ana y Valentina, estudiantes o como en el caso de Oscar y Camilo, turistas que luego se transformarán en migrantes sin papeles o continuarán su proyecto educativo dependiendo de becas y formas precarias de subsistencia. $\mathrm{Al}$ respecto Ana señala:

Tener estatus de refugio es un lío, averigüé de todas maneras con personas que sabían mucho del tema, pero me dijeron que no me iba a aportar demasiado el reconocerme como exiliada, ya que era un trámite muy largo y engorroso, en cierta medida (re)victimizante (Entrevista realida por Liz Rincón Suárez, 2016).

A su vez, el desplazamiento forzado transfronterizo decanta en la precarización de la vida. $\mathrm{Al}$ respecto narra Valentina:

Gente con una carrera ya profesional, tenía la sensación de tener que retroceder porque en el otro país sus estudios y sus calificaciones no valían, entonces tenían que volver a estudiar o no encontraban las condiciones laborales, o trabajaban en condiciones muy precarias y sin derechos. Perdieron el estatus de alguna manera y muchos sentían que vivían afuera, pero sentían todavía su corazón estaba todavía en Colombia. Había proceso de depresión, había procesos de sentir indiferencias. Uno se encuentra con la estigmatización de ser colombiana en el exterior, de que todo allá es narcotráfico y todo eso, incluso un ejemplo de alguien que no encontraba como arrendar porque nadie quería darle un apartamento a alguien que fuese colombiano (Entrevista realizada por Liz Rincón Suárez, 2017).

De otro lado, una segunda tendencia es por la vía organizativa, en la cual se da la salida a través de los programas solidarios de protección de grandes plataformas de derechos 
humanos ubicados en España, Canadá y Europa Central. Otros estudios sobre el exilio colombiano relatan cómo existe una experiencia de desclase, pues el capital social, el recurso económico y el lugar de liderazgo se rompen a partir de las partidas (Asprilla, 2000; Gómez Albarello \& García Rodríguez, 2011). Leo narra cómo hizo parte de uno de los programas de refugio:

El grupo en el que fuimos nosotros, estuvimos y arrancamos primero dos, porque a los otros no les dieron rápido la visa que nos dan especial para nosotros. Entonces arrancamos los dos y nos pusieron en un piso franco con nueve personas, hay dos pisos francos. Empieza uno a ver las peleas, la comida, el baño, el orden, el desorden, lavar la ropa, todas esas huevonadas y se rompen, entonces cuando se rompen empiezan a pelear a no hablarse, a las invitaciones va el uno, pero si no va el uno no va el otro, pero la idea es que vayamos todos en grupo, bueno son la cagada. El programa cubría un año y un subsidio de 800 euros, solo es para colombianos y apoyan a Venezuela, Ecuador, a Cuba, Nicaragua y Bolivia (Entrevista realizada por Liz Rincón Suárez, 2015).

Como puede observarse, el inicio de la salida de defensores de derechos humanos a España es heterogénea. En su mayoría, sin embargo, está marcada por el silencio de ausencia, un mapa donde se repiten una y otra vez los giros en las historias frente a ciertas preguntas, la interrupción en el relato porque se olvidó el café en la cafetera o la elección de preferir hablar desde esa voz del testimonio, tan conocida y cómoda, tan dominada desde el lugar moral de la víctima o desde la capacidad de lucha del sobreviviente. Este silencio además es un pacto que conservan aquellos que alguna vez portaron armas en las guerrillas o se desmovilizaron en los procesos de los ochenta y noventa, pues es una autocensura necesaria para la protección, así sus agendas ya no tengan que ver con la opción armada.

Un ejemplo de los silencios es la censura de Patricia proveniente del Urabá antioqueño. Patricia nunca habla de su experiencia personal ni se presenta a partir del testimonio de la víctima, sin embargo, su expresión corporal cambia cuando se habla de las masacres de los paramilitares. La única referencia de Patricia acerca de la guerra en su discurso, es durante la proyección del documental Impunity en Barcelona en junio de 2012. Patricia, cuenta como su prima nació en Apartadó en medio de un combate "¡se escuchaban las balas, dígame si alguien va a tener una vida normal después de nacer en esa casa, con ese miedo que sentíamos todos!”

Como en el relato de Rodrigo, el silencio, emerge como censura frente a temas específicos, como los detalles más cercanos a la emoción de duelo del destierro o los motivos por los cuáles fue exiliado. Aún en la imaginación de los exiliados la asociación del activismo con el auxilio del terrorismo ha afectado su manera de socializar su trabajo. Una respuesta similar fue observada por Lunday (2008) quien identifica a través del texto de Seamus Heaney y el contexto de IRA en Irlanda, cómo los silencios pueden venir atravesados por las emociones de la culpa o el miedo. En el segundo de los casos, admitirá que quienes habitan el miedo tendrán mayor deliberación que los que habitan en culpa, estos últimos producirán silencios inconscientes o reprimidos. Existe entonces un guión bastante claro sobre 
qué decir, qué elementos resaltar y cómo discutirlo en público. Esta manera de comunicar tiene multitud de silencios sobre la propia experiencia, tal como refiere Kristeva (1991):

En la imposibilidad de concatenar, la frase se interrumpe, se debilita, se detiene. Los sintagmas no alcanzan a formularse. Un ritmo repetitivo, una melodía monótona domina las secuencias lógicas quebradas y las transforman en letanías recurrentes, obsesivas. En fin, cuando esta musicalidad frugal a su vez se debilita o simplemente no logra instalarse a fuerza de silencio, el melancólico parece suspender la articulación de cualquier idea naufragando en la nada de la asimbolía (...) en la demasía de un caos de ideas imposible de ordenar (p. 30).

Sin embargo, los silencios identificados en las trayectorias de migrantes y exiliados no tienen que ver únicamente con la imposibilidad de narrar acontecimientos dolorosos o traumáticos. En muchos casos, este silencio es una respuesta consciente, de tal modo que "un verdadero vacío, un silencio puro, no es posible -ni siquiera conceptualmente o como un hecho (...). El silencio sigue siendo, inevitablemente, una forma de discurso -en muchos casos, de denuncia o acusación-, y un elemento en un diálogo" (Sontag, 1969, p. 59). Así el ejercicio del silencio en las narrativas de los defensores es una forma de protección ante una posible (re)victimización, pero a su vez el conocimiento silenciado hace parte del patrimonio del grupo, de tal manera que dichos acontecimientos son contenidos como secretos, que tienen una alta significación para la construcción de la identidad y de la comunidad de exiliados.

La voz entonces se expresa desde la repetición de lo conocido, denota una profesionalización del testimonio, contado una y otra vez ante las grabadoras, las plazas públicas, los eventos, las salas judiciales es casi como una formula, los defensores exponen el caso, establecen los responsables y exigen memoria, verdad, justicia y reparación. El silencio, sin embargo, traza otro camino de interpretación, uno casi imposible de descifrar, pues se expresa a través de otros espacios, en la intimidad del final de una noche de fiesta, en los labios apretados, en las manos que se empuñan y en las que se abrazan el vientre, en el baile, en los susurros y en el chiste negro.

En consonancia con la voz, el silencio también es la expresión del miedo que permanece. Jaume, me cuenta en una reunión política, como cuarenta efectivos de la inteligencia colombiana, se encuentran haciendo seguimientos en Barcelona. Debido a que en el exilio también se han dado procesos de vigilancia a los defensores, por lo general las interacciones se encuentran altamente ritualizadas, esto puede observarse en la existencia de pautas repetidas sobre cómo hablar acerca del pasado violento en espacios que no pertenecen a prácticas políticas y a las públicas de memoria.

En el ámbito cotidiano, hablar de la experiencia de dolor causa disrupción, muchas veces es censurado; así, expresar o narrar los hechos solo es posible en el ámbito público de la conmemoración o la denuncia. Aún entre víctimas existe una zona de silencio que es respetada y que se establece como un tabú. Los elementos del testimonio que no pertenecen a, por decirlo de algún modo, un relato oficial repetido en conmemoraciones y denuncias, son posibles únicamente en contextos de alta intensidad emocional donde se establecen profundos niveles de intimidad entre muy pocas personas. 
Dentro de estas constelaciones, el tiempo experimentado en el ciclo de la melancolía del exilio parece transcurrir en un tiempo eterno, una angustia presente incapaz de imaginar el futuro. Esta experiencia temporal deriva en el habitar el tiempo de la víctima, un eterno presente rutinizado, donde el cuerpo se ancla a un lugar fijo en el miedo neurótico del exiliado (Said 2005), o en la habitación negra (Kristeva, 1991). En el caso de los participantes en esta investigación. Este no es un estado permanente, es un estado de tránsito, hace parte de los ciclos del exilio. En él, el mundo imaginario está lleno de fantasmas y recuerdos, tal como experimentó Antonia "veo a mis hijos en la calle como fantasmas":

Ese tiempo era mi segundo periodo, aunque no se me notara yo tenía ahí una carga terrible de dolor y de vacío, primero por mi madre, después por los chicos. Yo me descubría caminando por la calle, detrás de un chico que tenía la misma edad de Migue o de Pablo, (sus hijos) con la misma hatta palestina, el pelito largo. Me iba detrás de él. Es como si se me apareciera Pablo o como si se apareciera Migue, entonces al ver que no eran, me devolví (Entrevista realizada por Liz Rincón Suárez, 2012).

Siguiendo la historia de Antonia, los relatos sobre las sensaciones del exilio, refieren a una comunidad política que se ha constituido como una comunidad de sufrimiento -La familia de la sangre derramada-. La persecución masiva y el asesinato de sus compañeros, ha sido una experiencia profundamente dolorosa, "una desgracia tan violenta que ni siquiera puede soportarse como recuerdo" (Weil, 2007, p. 13). Todo el contexto de la persecución afecta los órdenes simbólicos, también los procesos sociales con sus proyectos y genera un estado de herida abierta.

La organización de la experiencia traumática se dará a través de la asunción de una nueva identidad: la del exiliado y la del inmigrante, que en algunos casos no se resolverá aún con el paso del tiempo. El sujeto comenzará a habitar en palabras de Kristeva (1991), un estado de melancolía, que describe como un sol negro. Así las cosas, lo que se fractura en los esquemas de sentido es la capacidad de decidir y actuar en coherencia con esas decisiones, la intención de llevar a cabo el "proyecto", debido a que su desarrollo se encuentra alterado por la amenaza y el destierro.

La melancolía es un estado profundo de tristeza, algunos lo narran como el habitar la ausencia, en este caso de la tierra y las relaciones tejidas en su espacialidad. En este estado, se idealiza al territorio abandonado. Los sabores colombianos se sobrevaloran, se buscan en las redes de abastecimiento migrantes, en los viajeros que recién llegan a la ciudad. Por lo general, esta melancolía también tiene que ver con la pérdida del hogar y de las relaciones cotidianas. Los gestos de la sociedad receptora se vuelven agresivos "es como ser una tortuga sin caparazón, todo te hace daño, la expresión dura de los catalanes, que te corrijan tu castellano, que te obliguen a decirle al español castellano, o que no sepan dónde queda Colombia o te pregunten si vivimos en chozas", dice Valentina.

La tristeza del país abandonado también es expresada por Emiliano en el Encuentro de Migrantes Críticos en Nueva York. Emiliano narra cómo tuvo que llegar a Estados Unidos sin querer "el sueño americano" sino porque vio morir uno a uno a sus compañeros de la Unión Patriótica. A Emiliano se le corta la voz mientras interviene, han pasado quizás 
15 años después de su salida al exilio, pero el sufrimiento parece permanecer allí como si hubiese ocurrido hace pocos años.

Emiliano no es el único, sus compañeros reunidos al otro lado del océano en Barcelona, también relatan cómo se había matado a la resistencia, a las opciones políticas diferentes. El sufrimiento personal deja de ser un hecho aislado y vivenciado de manera solitaria, para transformarse en un sufrimiento social, experimentado de manera colectiva y que comparte las mismas heridas, los mismos traumas.

Esta experiencia de la melancolía y el silencio que se vivencian a nivel individual y colectivo, tienen que ver con lo que Erikson (2011) define como trauma social de manera similar a lo que otros autores han denominado trauma colectivo (Alexander, 2004, 2011; Erikson, 2011; Jensen, 2003; Ortega, 2011; Sztompka, 2000; Vetzberger, 1997; Zarowsky, 2005)como una condición persistente además de un acontecimiento grave, lo representará como una "lesión penetrante" en la constelación de experiencias vitales. En esa medida, afirma que "algunas veces los tejidos de la comunidad pueden dañarse de una forma muy parecida a los tejidos de la mente y el cuerpo (Erikson, 2011, p. 66). Un fragmento de Yezid Arteta (2013), exiliado resume lo experimentado por los activistas desterrados:

Los asesinatos pasaban con tanta velocidad que no alcanzaban a verlos. Esta categoría de exiliados pasó muchos días en las funerarias y los cementerios de Colombia de tal modo que no les quedó tiempo para hacer el duelo o adquirir conciencia de lo que estaba pasando. Cuando encontraron la tranquilidad en otros mundos se les partió el alma y empezaron a llorar a sus amigos muertos y hubo casos de exiliados de esta índole que terminaron en el manicomio. A los que venían con esquizofrenia o creían ver enemigos por los cuatro costados, el exilio los fue calmando y con el tiempo se volvieron mansos y tolerantes (Revista Semana Edición Virtual).

Así las cosas, el exilio funciona como un paréntesis para asumir el trauma social. Esto puede evidenciarse en las fugas, o puntos de la trayectoria que son incomprensibles para los defensores de derechos humanos y que comienzan a articular las emociones asociadas al sufrimiento en interacciones, espacios o incluso en sus propias corporalidades. En una carta escrita a su hijo asesinado, Leo afirma "El sol no calienta igual, el azúcar no endulza igual, las noches son más oscuras. Los días son vacíos, las noches son peores”. Ese estar en el mundo desde la fractura, evidencia que al mismo tiempo que el exilio permite hacer duelos, también puede asumirse como una constelación de experiencias traumáticas que afectan no solo a las personas que lo sufren sino a sus entornos sociales -asesinato de familiares - amenazas, destierro, desestructuración de la familia-, tal como señalara Brown "es un acontecimiento que está por fuera del rango normal de la experiencia humana" (2011, p. 480).

Concordando con Kaufman (1998), ante el duelo intolerable, los defensores comprenden su propia historia a través de la historia de los otros sufrientes. Si bien frente a los acontecimientos traumáticos los referentes de filiación se desdibujan y los procesos y espacios de simbolización se desarticulan, el encuentro con el otro a partir de la narración del testimonio hace que el que escucha sea un eslabón de la transmisión de lo traumático. Así "las 
condiciones traumáticas se desplazan del propio ser y al hacerlo, les da a las víctimas la sensación de que se las ha separado y hecho especiales" (Erikson, 2011, p. 67). De tal forma que la búsqueda de otros especiales conduce al establecimiento de comunidades de sentido. La negociación de la identidad del exiliado se resuelve entonces a partir de su giro hacia el activismo político y, al mismo tiempo, la trayectoria de sufrimiento personal se desplaza hacia lo público, buscando encuentros con otros significativos, construyendo, en palabras de Veena Das (2008), comunidades de dolor que mutarán en comunidades en resistencia y pondrán en escena pública todos los recursos simbólicos necesarios, con el fin de narrar el dolor que ahora es pasado en clave política.

Otra forma de analizar la familia de la sangre derramada o la comunidad sufriente es la perspectiva de las comunidades de sentido. Para Berger y Luckmann (1997) estas emergen a partir de la crisis de las instituciones y de la permanente sensación de anonimato en la sociedad moderna. Son por tanto comunidades de vida "que se desarrollan a través de una acción recíproca y mediada” (Berger \& Luckmann, 1997, p. 13) y que forman diversos niveles de sentido, no directamente prácticos, como sí afectivos, que es lo que puede notarse en las trayectorias de vida.

Así, pese a que el exilio representa un hecho victimizante, de serias implicaciones para el capital social y político de la nación colombiana, el fortalecimiento de la familia de la sangre derramada muta a la creación de comunidades de sentido, que actuarían como respuesta a fenómenos como el trauma social. En Barcelona, los exiliados harán parte de las redes de activismo, pues el encuentro con otros exiliados e inmigrantes en general reactivará los trabajos del recuerdo y las acciones políticas en torno a la paz y a la justicia. Estos trabajos han decantado en la participación de los exiliados en los diálogos de la Habana y en la Jurisdicción Especial para la Paz, teniendo un especial capítulo en la Comisión de la Verdad y en los procesos de leyes para la inmigración y para la protección y exigibilidad de derechos no sólo para el exilio político sino para los migrantes trabajadores y refugiados.

\section{Notas}

1. Este artículo se basa en los resultados de la tesis doctoral "Nuestro Techo el cielo, Nuestra Casa el Mundo, Trayectoria del exilio de colombianos en la Ciudad de Barcelona" del departamento de Antropología de la Universidad de los Andes de Colombia y en los testimonios recuperados por la autora en el marco del micrositio digital Voces del Exilio del Centro Nacional de Memoria Histórica de Colombia.

2. Este testimonio pertenece a la investigación "Voces del Exilio" para el microstitio digital del mismo nombre perteneciente al Centro Nacional de Memoria Histórica.

\section{Referencias Bibliográficas}

ACA. (2010). Amenzas de paramilitares en San Francisco, oriente antioqueño.

Alexander, J. (2003). The Meanings of Social Life: A Cultural Sociology. New York: Oxford University Press. 
Alexander, J. (2004). Toward a theory of social trauma. In Cultural Trauma (pp. 1-28). California: University of California Press.

Alexander, J. (2011). Trauma cultural e identidad colectiva. In F. Ortega (Ed.), Trauma, cultura e historia: Reflexiones interdisciplinarias para el nuevo milenio (pp. 125-164). Retrieved from http://es.scribd.com/doc/74090345/Trauma-Cultura-e-Historia-InTRO-2011

Arteta Dávila, Y. (2013). El exilio colombiano. Semana. Retrieved from http://www.semana. com/opinion/articulo/exilio-colombiano-opinion-yezid-arteta/357456-3

Asprilla, F. (2000). Exiliados y exiliadas colombianas en Madrid 1986-1996. Universidad Aut $\{$ ó noma de Madrid.

Bello, M. N., Martín Cardinal, E., Millán Echeverría, D., Pulido Herráez, B., \& Rojas Isaza, R. (2005). Bojayá, memoria y río. Violencia política, daño y reparación. Bogotá: Universidad Nacional de Colombia.

Berger, P., \& Luckmann, T. (1997). Modernidad, pluralismo y crisis de sentido. La orientación del hombre moderno. Barcelona: Paidos Ibérica.

Blair, E. (2002). Memoria y Narrativa: La puesta del dolor en la escena pública. Estudios Políticos, (21), 9-28.

Blair, E. (2003). La violencia frente a los otros lugares y los otros de la cultura.

Brown, L. (2011). Una perspectiva feminista del trauma. In F. Ortega (Ed.), Trauma, cultura e historia: Reflexiones interdisciplinarias para el nuevo milenio (pp. 479-496). Bogotá: Centro de Estudios Sociales.

Caruth, C. (1993). Violence and Time: Traumatic Survivals. Assemblage, 20, 24-25. https:// doi.org/10.2307/3181682

Castillejo, A. (2010). Guerra, cotidianidad y los ordenes globales. Colombia. Universidad del Cauca.

Das, V. (2008). Sujetos del dolor, agentes de dignidad. (F. Ortega, Ed.). Bogotá: Universidad Nacional de Colombia. Retrieved from https://www.academia.edu/206626/Veena_Das_ Sujetos_del_dolor_agentes_de_dignidad

Elias, N. (1994). Introduction: A Theoretical Essay on Established and Outsiders. A Sociological Enquiry into Community Problems. In N. Elias \& J. Scotson (Eds.), A theoretical Essay on Established and Outsider Relations. London: Sage Publications.

Erikson, K. (2011). Trauma y comunidad,. In F. Ortega (Ed.), Trauma, cultura e historia: Reflexiones interdisciplinarias para el nuevo milenio (pp. 63-84). Centro de Estudios Sociales. Retrieved from http://es.scribd.com/doc/74090345/Trauma-Cultura-e-HistoriaInTRO-2011

Feldan, A. (2004). Memory theaters, virtual witnessing, and the trauma - aesthetic. Project Muse, 27, 40.

Gómez Albarello, S., \& García Rodríguez, L. (2011). Relatos del ser ciudadano en el exilio. Facultad de Psicología. Retrieved from http://repository.javeriana.edu.co/handle/10554/7889

Grupo de Memoria Histórica. (2009). La masacre de el salado: esa guerra no era nuestra. Bogotá: Taurus.

Grupo de Memoria Histórica. (2010). La tierra en disputa. Memorias del despojo y resistencias campesinas en la costa caribe 1960-2010. Bogotá: Taurus.

Jensen, S. (2003). Nadie habrá visto esas imágenes, pero existen. A propósito de las memorias del exilio en la Argentina actual. América Latina Hoy, 34, 103-118. 
Kaufman, S. (1998). Sobre violencia social, trauma y memoria. Seminario: Memoria colectiva y Represión. Montevideo: SSRC.

Kristeva, J. (1991). Sol Negro. Depresión y melancolía. Venezuela: Monte Ávila Editores Latinoamérica.

Lunday, E. (2008). Violence and solence in seamus heaneys: Mycenae lookout. New Hibernia Review, 12.

Mcilwaine, C. (2014). Everyday urban violence and transnational displacement of Colombian urban migrants to London, UK. International Institute for Environment and Development (IIED), 26(2), 417-426.

Moreno León, C. E. (2012). Ámbitos de conflicto y repertorios de violencia en el Suroccidente Colombiano. Estudios Políticos, (41), 80-102.

Ortega, F. (2011). El trauma social como campo de estudios. In F. Ortega (Ed.), Trauma, cultura e historia: Reflexiones interdisciplinarias para el nuevo milenio (pp. 17-62). Retrieved from http://es.scribd.com/doc/74090345/Trauma-Cultura-e-Historia-InTRO-2011

Oslender, U. (2012). Espacializando la resistencia: perspectivas de espacio y lugar en las investigaciones de movimientos sociales. In Antropologías transeúntes (pp. 195-226). Bogotá, Colombia: Instituto Colombiano de Antropología e Historia.

Ovejero, J. (2012). La ética de la crueldad. Anagrama, Ed.

Park, R. (1928). El hombre marginal. S/D.

Radio Macondo. (2014). Amenazan a Defensores de los Derechos Humanos en Barrancabermeja. Retrieved from http://radiomacondo.fm/2014/01/09/amenazan-a-defensoresde-derechos-humanos-en-barrancabermeja/

Red de Bancos de Datos de Derechos Humanos y Violencia Política en el primer semestre de 2008 para la revista Noche y Niebla. (2008). Informe "Terror e inseguridad." Red de Bancos de Datos de Derechos Humanos y Violencia Política cinep.

Regan, T. (1980). Cruelty, Kindness, and Unnecessary Suffering. Philosophy, 55, 10.

Ries, N. (2002). Anthropology and the Everyday, from Comfort to Terror. New Literary History, 33, 19. Retrieved from http://muse.jhu.edu/journals/nlh/summary/v033/33.4ries. html

Roniger, L. (2009). El exilio y su impacto en la reformulación de perspectivas identitarias, políticas e institucionales. Revista Ciencias Sociales, 3(125), 83-101.

Roy, S. (2008). The grey zone: The "ordinary" violencie of extraordinary times. Journal of anthropological institute, 14, 316-333.

Said, E. (2005). Reflexiones sobre el exilio. (Debate, Ed.). Barcelona: DEBATE.

Schutz, A. (1974). La vuelta al hogar. In Estudios sobre teoría social. Buenos Aires: Amorrortu.

Schutz, A. (1999). El forastero. Ensayo de psicología social. In Estudios sobre la teoría social. Buenos Aires: Amorrortu.

Sharpe, P., \& Mascia-Lees, F. (2006). Introduction to "Cruelty, Suffering, Imagination: The Lessons of J. M. Coetzee." American Anthropologist, 108, 4.

Shepler, S. (2005). The Rites of the Child: Global Discourses of youth and reintegrating child soldiers in Sierra Leone. Journal of Human Rights, 4, 14. Retrieved from http:// www.academia.edu/243680/The_Rites_of_the_Child_Global_Discourses_of_Youth_ and_Reintegrating_Child_Soldiers_in_Sierra_Leone

Simmel, G. (2012). El Extranjero: sociología del extraño. España. Sequitur. 
Smelser, N. J. (2011). Trauma psicológico y trauma cultural. In F. Ortega (Ed.), Trauma, cultura e historia: Reflexiones interdisciplinarias para el nuevo milenio (pp. 85-124). Recuperado de http://es.scribd.com/doc/74090345/Trauma-Cultura-e-Historia-InTRO-2011

Sontag, S. (1969). The Aesthetics of Silence. In Styles of Radical Will. New York: Straus and Giroux.

Sztompka, P. (2000). Cultural trauma, The other face of social change. European Journal of Social Theory., 3, 449-466.

Tilly, C. (2002). Repertorios de acción contestataria en Gran Bretaña 1758-1834. In M. Trougot (Ed.), Protesta social, repertorios y ciclos de la acción colectiva (pp. 1-17). Madrid: Editorial Hacer.

Tilly, C. (2006). Regimes and Repertoires. Chicago. The Chicago University Press.

Um, K. (2012). Exiled memory: History, Identity, and Remembering in Southeast Asia and Southeast Asian Diaspora. Positions: East Asia Cultures Critique, 20(3), 831-850.

Van Alphen, E. (2011). Experiencia, memoria y trauma: síntomas de discursividad. In F. Ortega (Ed.), Trauma, cultura e historia: Reflexiones interdisciplinarias para el nuevo milenio (pp. 195-216). Centro de Estudios Sociales.

Vetzberger, Y. Y. I. (1997). The antinomies of collective political trauma: a pre - theory. Political Psychology.

Weil, S. (1996). Echar raices. Retrieved from http://es.scribd.com/doc/139005558/Echarraices-Simone-Weil-preludio-a-una-declaracion-de-deberes-hacia-el-ser-humano

Weil, S. (2007). La Ilíada o el poema de la fuerza. Retrieved from http://www.convencion bautista.com/yahoo_site_admin/assets/docs/Weil_Simone_-_La_Iliada_O_El_Poema _De_La_Fuerza.351224702.PDF

Zarowsky, C. (2005). Writing trauma: emotion, ethnography, and the politics of suffering among somali returnees in Ethiopia. Culture, Medicine and Psychiatry, 28, 189-199.

\begin{abstract}
On the base of migratory trajectories of colombians in Barcelona, Spain, this article demonstrates how political exile constitutes a violent event staged and prepared by the armed actors of the Colombian war. It occurs through the establishment of landscapes of fear and terror. In this process, the life sense is fractured, and the experience of the foreigner emerges like an estrangement that decant in the need to find creative practices to negotiate the nostalgia, the sensation of loss and the exile. In conclusion, international forced migration, in the prism of exile, have consequences for the social leader's existence. They have lived in precarious conditions. Aditionally, the migratory experience represents the nostalgia of the abandoned land and the lost project.
\end{abstract}

Keywords: International Forced Migration - Political exile - Colombian exile.

Resumo: Das trajetórias migratórias dos colombianos em Barcelona, Espanha, este artigo demonstra como o exílio político constitui um evento violento; encenada e preparada pelos atores armados da guerra colombiana, através do estabelecimento de paisagens de 
medo e terror. Nesse processo, o jogo quebra e a experiência do estrangeiro emerge, um estranhamento que decanta na necessidade de encontrar práticas criativas para negociar a nostalgia, a sensação de perda e exílio. Em conclusão, a migração internacional forçada, no prisma do exílio, terá como principais conseqüências a existência em condições precárias, a experiência migratória de habitar a partir da nostalgia da terra abandonada e do projeto perdido.

Palavras chave: Migração Internacional Forçada - exílio político colombiano - conflito armado colombiano.

[Las traducciones de los abstracts fueron supervisadas por el autor de cada artículo] 